\title{
The Epidemiology of Multiple Pregnancies
}

\author{
F. Parazzini ${ }^{1,2}$, A. Villa ${ }^{1,2}$, S. Moroni ${ }^{2}$, L. Tozzi ${ }^{1}$, S. Restelli ${ }^{1}$ \\ ${ }^{1}$ The "Mario Negri" Istitute of Pharmacological Research, Milan and ${ }^{2}$ Ist. Clinic of Obstetrics \\ and Gynaecology, University of Milan, Italy
}

\begin{abstract}
Over the last decades the frequency of multiple births has been on the decline in most developed countries. This trend, however, has been restricted to dizygotic twins, while monozygotic rates have remained stable or risen slowly. In more recent years, however, the fall in multiple dizygotic birth rates has ceased and a slight increase is observed. This trend and the increased frequency of triplets or higher-order births, registered from the early 1980 s onwards, are essentially related to treatments for infertility. No single risk factor, such as maternal age, parity, oral contraceptive use, or declining fertility rates can explain the overall declining trends. In this paper we review the descriptive epidemiology and the main risk factors for multiple pregnancies.
\end{abstract}

Key words: Epidemiology, Risk factors, Multiple pregnancies

\section{INTRODUCTION}

The decline in the frequency of multiple births in most developed countries over the last decades has been restricted to dizygotic (DZ) twins, while monozygotic (MZ) rates have remained stable or risen slowly $[1,2,5,6,10,11]$. Data in more recent years from the United Kingdom, Denmark and Canada have suggested that the decrease in multiple DZ birth rates has stopped, and, if anything, a slight increase was observed, while triplet rates have markedly risen from the early 1980 s onwards [3,7,12].

These simple epidemiological observations have suggested that changes in lifestyle and/or reproductive habits in the last decades have markedly influenced DZ twinning rates. In this paper we review the descriptive epidemiology and main risk factors for multiple pregnancy. Special focus is given to the trends in multiple pregnancy rates in Italy. 


\section{Geographic and temporal trends in Italy and other countries}

In Italy between 1955 and 1985 the frequency of multiple births declined from $12.6 / 1000$ deliveries ( 1 every 79 deliveries) to $9.4 / 1000$ deliveries ( 1 every 106 deliveries) [17]. This downward trend was constant until the early 1970s when rates tended to level off and then to slightly increase again in the early 1980s (Fig. 1). In the late 1980s, however, an increasing trend was observed, and in 1989 the rate of multiple births was $10.4 / 1000$ deliveries. However, these trends were largely attributable to $\mathrm{DZ}$ rates as $\mathrm{MZ}$ births were relatively constant over the considered period (Fig. 2). The proportion of triplets or higher order births on the total of multiple births was constant from 1955 to the late $1970 \mathrm{~s}$, after which it rose markedly, being 1:99 in the quinquennium 1955-1959, 1:103 in 1975$1979,1: 70$ in 1980-1983 and 1:38 in 1989 (Tab. 1).

Similar trends in absolute and relative terms have been reported from North European and American countries [3,7,12,14]. For example, in England the frequency of multiple pregnancies was $12.2 / 1000$ pregnancies in 1956-1959, declining to 9.7 in 19761980 , but increasing to 10.2 in $1983-1985$, with an estimated MZ rate of about 3.5$3.8 / 1000$ pregnancies over the entire period 1955-1985 [3].

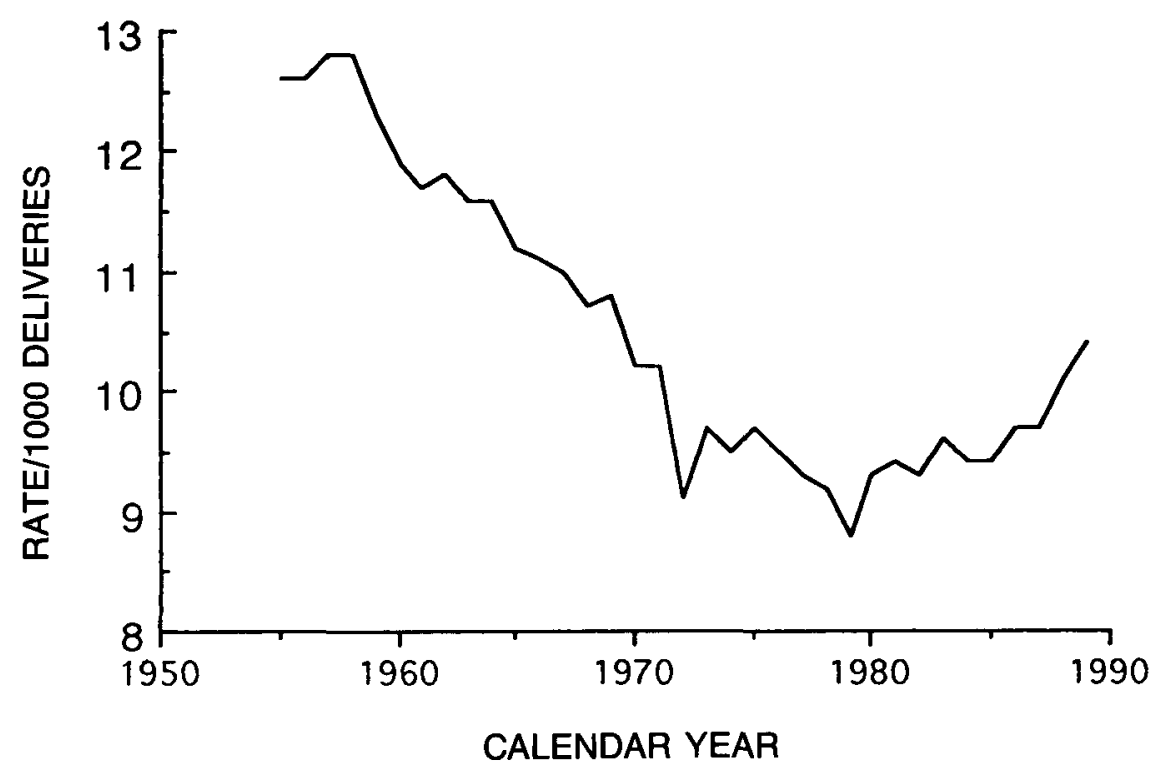

Fig. 1. Trend in multiple pregnancy rates in Italy, 1955-1989. 


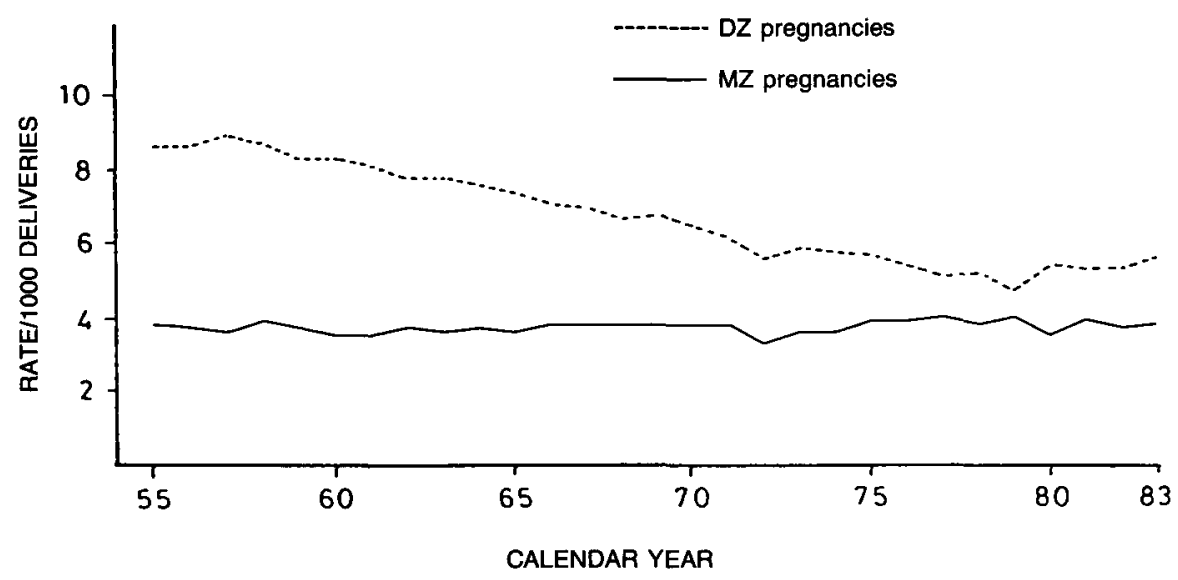

Fig. 2. Trend in dizygotic and monozygotic twinning in Italy, 1955-1983.

Table 1 - Trends in multiple birth rates in Italy, 1955-1989

\begin{tabular}{|c|c|c|c|c|c|c|c|}
\hline \multicolumn{8}{|c|}{ Calendar period } \\
\hline & $1955-59$ & $1960-64$ & $1965-69$ & $1970-74$ & $1975-79$ & $1980-83$ & 1989 \\
\hline $\begin{array}{l}\text { Multiple birth rates/ } \\
1000 \text { pregnancies }\end{array}$ & 12.6 & 11.8 & 11.0 & 9.8 & 9.3 & 9.4 & 9.6 \\
\hline $\begin{array}{l}\text { DZ rates/ } \\
1000 \text { pregnancies }\end{array}$ & 8.8 & 8.1 & 7.2 & 6.1 & 5.4 & 5.4 & n.a. \\
\hline $\begin{array}{l}\text { Triplets or higher- } \\
\text { order birth rates/ } \\
1000 \text { pregnancies }\end{array}$ & 0.13 & 0.12 & 0.11 & 0.09 & 0.09 & 0.13 & 0.27 \\
\hline
\end{tabular}

n.a. = not available

\section{RISK FACTORS}

\section{Age}

As for most obstetric conditions, "advanced" maternal age is a prime risk factor for multiple pregnancy. Multiple birth rates in various strata of maternal age in Italy are presented in Table 2. The highest rates were in the 35-39 years age group, but flattened out in the subsequent age strata. The differences within the various age groups were more marked for DZ multiple pregnancies: in 35-39-year-old women rates were more than threefold higher than in those aged 20 or less. Monozygotic rates were slightly upward till age 35-39, but the differences were limited [17]. These findings are common in various populations [3].

No obvious reason has been identified to explain the decreasing rates of dizygotic births found in women of 40 years or more. Selective mechanisms, such as, the greater 
Table 2 - Multiple birth rates according to maternal age and zygosity in Italy, 1980-1983

\begin{tabular}{lccc}
\hline Maternal age & $\begin{array}{c}\text { Total number } \\
\text { of deliveries }\end{array}$ & \multicolumn{2}{c}{ Multiple births/1000 deliveries } \\
\cline { 3 - 4 } & 159.069 & $\mathrm{DZ}$ & $\mathrm{MZ}$ \\
\hline$\leq 19$ & 747.066 & 2.5 & 3.6 \\
$20-24$ & 823.302 & 4.2 & 3.6 \\
$25-26$ & 505.582 & 5.4 & 4.2 \\
$30-34$ & 185.916 & 7.3 & 4.1 \\
$35-39$ & 43.853 & 6.1 & 3.5 \\
$40-44$ & 3.177 & n.e.* & $4.7^{* *}$ \\
\hline 45 & &
\end{tabular}

* Not estimated (no unlike-sex multiple birth was observed in this age strata in the considered period)

** Probably including some like-sex dizygotic pregnancies.

frequency of abortions in multiple pregnancies in older women, and genetic and enviromental factors can all be suspected, but these hypotheses are merely speculative.

\section{Socioeconomic factors}

A higher frequency of multiple pregnancies in the lower social classes has been reported in studies conducted in Nigeria and Scotland and reported also among illegitimate maternities $[8,16]$. It has been suggested that these differences might be explained in terms of the different reproductive or dietary habits of women in the lower social classes, but this relation between social class and multiple pregnancy has not been consistently reported. For example, in the United Kingdom multiple birth rates were comparable in the different social classes [15].

\section{Reproductive history}

Clinical observations have suggested that high parity is associated with an increased risk of multiple DZ pregnancies. For example, a higher incidence of multiple pregnancies associated with parity has been shown in a comparative study of multiparous women conducted in India and Scotland [13], however, these findings are far from consistent [18]. The relationship between parity and multiple pregnancy can be interpreted in terms of non-adjustment or incomplete adjustment for the confounding effect of maternal age.

A potential association between spontaneous abortions and multiple pregnancies has been suggested on the basis of a geographical correlation observed between larger numbers of spontaneous abortions and smaller numbers of twin births [24], but the the scanty data available from formal epidemiological studies have not confirmed this suggestion [18] and, in the absence of a biological interpretation, this observation necessarily remains speculative. 


\section{Oral contraceptive use}

It has been suggested that oral contraceptive use may increase the risk of multiple births. Terminating oral contraceptive use might determine an increase in the gonadotropin level which, in turn, causes a multiple ovulation. An analysis conducted in Connecticut found that the risk of multiple births was about three times higher in women conceiving within two months of terminating oral contraceptive use [4]. Similar evidence emerged from a postal survey carried out in the United States [19] and from the Royal College of General Practitioners' Oral Contraceptive Study conducted in England in 1974. However, no relationship between oral contraceptive use and multiple births was found in another study conducted in the United Kingdom [22] and an inverse association was reported from a French study [9].

\section{Family history of multiple pregnancies}

A family history of multiple pregnancies is traditionally considered a "risk factor" for twinning. This clinical observation has been confirmed in epidemiological studies [18]. The risk of multiple births is roughly doubled in women whose mother and sisters have had twins, and this risk seems to be greater for monozygotic pregnancies than dizygotic ones. This relationship may be, in part, overestimated. In fact, in epidemiology studies it is extremely difficult to exclude the possibility of memory bias; in other words, women who have had twins may recall a family history of multiple pregnancies more easily than women who have had single pregnancies.

\section{Other factors}

It has been suggested that mothers of twins are of heavier weight and have an earlier menarche and menopause [23]. These findings have been discussed in terms of different gonadotropin level patterns in overweight women and their interaction with menstrual characteristics. However, the evidence available on this issue is largely inconsistent. Likewise, in some recent studies on the risk of multiple pregnancy, data obtained on the role of dietary habits and of a lower mean number of spermatozoas is both poor and inconsistent.

\section{CONCLUSIONS}

In later years, epidemiology has offered some of the most interesting findings to help clarify the mechanisms regulating the development of multiple pregnancies. The marked decreasing trends observed in DZ pregnancy rates up until the early 1980s suggest that environmental factors play a role in determining this condition. On the contrary, the constant frequency of $\mathrm{MZ}$ pregnancies over time and in different geographic areas suggests that monozygotic pregnancies are largely determined by genetic mechanisms. The increase in triplets or higher order births registered from the early 1980 s onwards is es- 
sentially related to treatments for infertility $[20,21]$. This has probably also had some impact, although difficult to quantify, on the changed trends in twin births as well.

No single risk factor, such as maternal age, parity, oral contraceptive use, or declining fertility rates explain the trends observed and these, therefore, can only tentatively be related to lifestyle habit changes.

In the near future, epidemiological research will be obliged to activate etiological studies on the risk factors for this condition. In terms of descriptive epidemiology, it is important to continue monitoring the frequency of the condition in order to understand if, for example, the "flattening" observed in the early 1980 s was effectively the beginning of a new trend. Finally, it would be interesting to quantify the effect of infertility treatments on the frequency of multiple dizygotic pregnancies.

Acknowledgment: This work was conducted within the framework of the CNR (Italian National Research Council) Applied Project "Prevenzione e controllo dei fattori di malattia", subproject "Fattori di rischio nella patologia materno infantile". Ms. Ivana Garimoldi provided helpful editorial assistance.

\section{REFERENCES}

1. Alberman E (1987): Multiple births. Br Med J 295:510.

2. Bonnelykke B, Sogaard J, Nielsen J (1987): Seasonality in twin birth rates, Denmark, 19361984. J Epidemiol Community Health 41:338-343.

3. Botting BJ, Macdonald Davies I, Macfarlane AJ (1987): Recent trends in the incidence of multiple births and associated mortality. Arch Dis Child 941-950.

4. Braken MB (1979): Oral contraception and twinning: An epidemiologic study. Am J Obstet Gynecol 133:432-434.

5. Editorial (1976): World decline in dizygotic twinning. Br Med J 1:1553.

6. Elwood JM (1983): Changes in the twinning rate in Canada, 1926-70. Br J Prev Soc Med 27: 236-241.

7. Elwood JM (1983): The end of the drop in twinning rates? Lancet I: 470.

8. Eriksson AW, Fellman J (1967): Twinning in relation to the marital status of the mother. Acta Genet Stat Med 17:385-398.

9. Hemon D, Berger C, Lazar P (1979): Analyses des variation géographiques de la fréquence des accouchements gémellaires en France. Une approche indirecte de l'étude des avortements spontanés. Rev Epidemiol Santé Publique 27:91-99.

10. James WH (1972): Secular changes in dizygotic twinning rates. J Biosoc Sci 4: 427-434.

11. James WH (1978): A hypothesis on the declining dizygotic twinning rates in developed countries. Prog Clin Biol Res 24B: 81-88.

12. James WH (1980): Hypothesis on the causes of the decline in dizygotic twinning rates. Rev Epidémiol Santé Publique 28:497-502.

13. MacGillivray I, Samphier M, Little J (1988): Factors affecting twinning. In: MacGillivray I, Campbell DM, Thompson B (eds): “Twinning and Twins"'. New York: John Wiley \& Sons, pp. 67-90.

14. Métneki J, Czeizel A (1983): Twinning rates. Lancet I, 935.

15. Murphy M, Botting B (1989): Twinning rates and social class in Great Britain. Arch Dis Child 64: 272-274.

16. Nylander PPS (1978): Causes of high twinning frequencies in Nigeria. In: Nance WE (ed): Twin research: Part B, Biology and Epidemiology. New York: Alan R. Liss, pp. 35-43. 
17. Parazzini F, Tozzi L, Mezzanotte G, Bocciolone L, La Vecchia C, Fedele L, Benzi G (1991): Trends in multiple births in Italy: 1955-1983, Br J Obstet Gynaecol 98:535-539.

18. Parazzini F, Tozzi L, Ferraroni M, Bocciolone L, Molteni E, Moreschi C, Fedele L (1993): Risk factors for multiple births. Acta Obstet Gynecol Scand 72:177-180.

19. Rothman KJ (1977): Fetal loss, twinning and birth weight after oral contraceptive use. N Eng J Med 297:468-471.

20. Smith T (1989): More triplets than ever. Br Med J 298:1665-1671.

21. Tuppin P, Blondel B, Kaminski M (1993): Trends in multiple deliveries and infertility treatments in France. Br J Obstet Gynaecol.

22. Webster F, Elwood JM (1985): A study of the influence of ovulation stimulants and oral contraception on twin births in England. Acta Genet Med Gemellol 34:105-108.

23. Wyshak G (1981): Reproduction and menstrual characteristics of mothers of multiple births and mothers of singletons only: A discriminant analysis. In: Gedda L, Parisi P, Nance WE (eds): Twin research 3: Part A, Twin Biology and Multiple Pregnancy. New York: Alan R. Liss, pp. 95-105.

24. Zahalkova M, Zudova Z (1984): Spontaneous abortions and twinning. Acta Genet Med Gemellol 33:25-26.

Correspondence: Dr. Fabio Parazzini, Istituto“Mario Negri”, Via Eritrea 62, 20157 Milan, Italy. 